\title{
Los demás animales como miembros de la comunidad política: superando el antropocentrismo constitucional a través de la paz como fin del Derecho
}

\author{
Israel González Marino \\ Universidad Central de Chile, Región de Coquimbo, Chile \\ israel.gonzalez@ucentral.cl \\ Master en Derecho Animal y Sociedad (UAB) \\ ORCID: 0000-0002-8769-4425 \\ Katherine Becerra Valdivia \\ Universidad Católica del Norte, Sede Coquimbo, Chile \\ kbecerra@ucn.cl \\ Ph.D. en Ciencia Política (Universidad de Missouri) \\ ORCID: 0000-0002-2329-705X
}

Recepción: Septiembre 2021

Aceptación: Septiembre 2021

Cita recomendada. GONZÁLEZ MARINO, I., BECERRA VALDIVIA, K., Los demás animales como miembros de la comunidad política: superando el antropocentrismo constitucional a través de la paz como fin del Derecho, dA. Derecho Animal (Forum of Animal Law Studies) 12/3 (2021). - DOI https://doi.org/10.5565/rev/da.587

\section{Resumen}

El "giro político" del movimiento animalista ha cuestionado el antropocentrismo constitucional que excluye a los demás animales -los no humanos-. Este trabajo reflexiona acerca de la consideración de los animales no humanos en tanto miembros de nuestras comunidades estatales, revisando para ello el concepto de constitución y su rol en relación a la paz como fin último del Derecho. Desde una comprensión profunda de nuestras relaciones con las demás formas de vida, es innegable que humanos y no humanos somos habitantes del planeta, y que en muchos casos conformamos comunidad e incluso familia. Tal circunstancia es razón suficiente para que los textos constitucionales incorporen y protejan a los demás animales, dado que por su carácter de seres sintientes, sus vidas también se ven afectadas por el poder político y estatal. Esta nueva visión también impone nuevas obligaciones al Estado y un cambio en las relaciones de poder de los particulares hacia los demás animales.

Palabras clave: comunidad política; constitución; paz; fines del Derecho.

Abstract - Other animals as members of the political community: overcoming constitutional anthropocentrism through peace as a purpose of law

The "political turn" of the animal movement has questioned the constitutional anthropocentrism that excludes other animals - nonhuman animals. This paper reflects on the consideration of other animals as members of our state communities, thus reviewing the concept of constitution and its role in relation to peace as the ultimate aim of law. From a profound understanding of our relationship with other life forms, it is undeniable that humans and nonhumans are inhabitants of the planet, and that in many cases we form communities and even families together. This circumstance is reason enough for constitutional texts to incorporate and protect other animals, given that due to their nature as sentient beings, their lives are also affected by political and 
state power. This new perspective also imposes new obligations on the state, and a change in power relations between individuals and other animals.

Key words: political community; constitution; peace; purpose of Law.

\section{Sumario:}

1. Introducción

2. Constitución, antropocentrismo constitucional y los demás animales

3. Comunidad más allá de la ciudadanía y la especie

4. La constitucionalización de la protección de los demás animales

5. Propuesta: la paz como fundamento constitucional de inclusión de los animales no humanos

6. Conclusiones

Bibliografía

\section{Introducción}

El Derecho es un fenómeno que concierne a la conducta humana y que se encuentra presente en toda organización de vida en sociedad ${ }^{1}$. Según FERREYRA, el Derecho procede directamente de la naturaleza humana y es el mayor invento para la ordenación de las comunidades humanas ${ }^{2}$. En tal sentido, se trata de una eminente creación de la razón y experiencia del ser humano ${ }^{3}$.

Operativamente, el Derecho es "un sistema de reglas sobre la fuerza, que se materializa por el discurso de los poderes estatales y constituye el medio más idóneo para perseguir un objetivo mínimo: la paz relativa, dado que se relaciona con una comunidad determinada de hombres"4. Provee paz pues, al monopolizar con éxito el uso de la fuerza, termina con la guerra de todos contra todos, impidiendo la aplicación de la ley del más fuerte 5 .

Toda comunidad de ciudadanos que alcanza cierto grado de convivencia se encuentra inclinada a la organización constitucional ${ }^{6}$. En palabras de FERRAJOLI, la Constitución consiste en "un sistema de reglas, sustanciales y formales, que tiene por destinatarios a los titulares del poder"7. Esta organización y unidad comunitaria -con fundamento coherente en una Constitución basada en múltiples y contradictorias ideas sobre libertad, igualdad, pluralismo y tolerancia- no supera los 250 años, es decir, es un instrumento relativamente reciente $^{8}$. Así, la historia del constitucionalismo es la historia de una progresiva extensión de la esfera de derechos. Una historia de conquistas alcanzadas por movimientos revolucionarios: liberales, socialistas, feministas, ecologistas y pacifistas ${ }^{9}$.

En la actualidad, el movimiento animalista tensiona los límites de la esfera de atribución de derechos morales y jurídicos. Esto es así pues las valoraciones científicas, filosóficas y culturales que tenemos acerca de los demás animales -los no humanos- han cambiado gracias a los desarrollos teóricos de autores y autoras

\footnotetext{
${ }^{1}$ SQUELLA NARDUCCI, H. Introducción al Derecho (Santiago 2014), 12.

${ }^{2}$ FERREYRA, R. G., Sobre la coexistencia pacífica: propósito de un constitucionalismo ciudadano, en Academia, Revista sobre enseñanza del Derecho 16/31 (2018), 75. https://dialnet.unirioja.es/servlet/articulo?codigo $=6867300$

${ }^{3}$ FERREYRA, R. G., Fundamentos constitucionales (Buenos Aires 2013a), 25.

${ }^{4}$ Op. cit. FERREYRA (2018) 73-74.

${ }^{5}$ Op. cit. SQUELLA NARDUCCI (2014) 636.

${ }^{6}$ Op. cit. FERREYRA (2013a) 269.

${ }^{7}$ FERRAJOLI, L., Razones jurídicas del pacifismo (Madrid 2004), 101.

${ }^{8}$ FERREYRA, R. G., Sobre la constitución. Concepto, composición y mecanismos, en Revista de Derecho Político 86 (2013b), 331. https://doi.org/10.5944/rdp.86.2013.12139

${ }^{9}$ Op. cit. FERRAJOLI (2004) 102-104.
} 
como SINGER ${ }^{10}$, REGAN $^{11}$, FRANCIONE ${ }^{12}$ o NUSSBAUM ${ }^{13}$, en función de los hallazgos en materia de sintiencia animal, esto es, la capacidad que poseemos muchas especies de animales de tener experiencias subjetivas o de experimentar lo que nos sucede ${ }^{14}$.

Pero más allá de los cambios y avances legislativos en materia de protección de los demás animales, su presencia en la vida del ser humano ha derivado incluso en un proceso de constitucionalización de la denominada "cuestión animal" 15 . Este proceso comenzó en Suiza en 1992, avanzando luego a Alemania en 2002 y a Luxemburgo en $2007^{16}$. Recientemente, algunos países ya incluyen en sus constituciones referencias expresas a los demás animales y ciertos mandatos de protección, pero el mayor desafío sigue siendo la constitucionalización de sus derechos ${ }^{17}$.

Además del nutrido debate relativo a los derechos de los animales no humanos, en los últimos años se ha venido desarrollando una nueva arista, fundamentalmente gracias a la obra Zoopolis de DONALDSON \& KYMLICKA $^{18}$ : el llamado "giro político". Esta ha sido, probablemente, la mayor aportación a este debate ${ }^{19}$, al extender la cuestión animal más allá de las discusiones sobre su bienestar, consideración, o derechos morales; alcanzando a su estatus político ${ }^{20}$.

En este trabajo se reflexiona acerca de la consideración de los demás animales en tanto miembros de nuestras comunidades estatales, revisando para ello el concepto de constitución y su rol en relación a la paz como fin último del Derecho. En el siguiente apartado se revisa el concepto de constitución y se evidencia la crítica formulada por el giro político de la cuestión animal al antropocentrismo constitucional. Luego, se analiza el concepto de comunidad y su extensión a los demás animales. Enseguida, se efectúa una revisión de la literatura respecto a la constitucionalización del Derecho Animal. Finalmente, se presenta la propuesta de este artículo en que se revisa el concepto de paz como fin del Derecho y cómo este se entrelaza con la constitución y el resto de los animales. Se termina con algunas conclusiones.

\section{Constitución, antropocentrismo constitucional y los demás animales}

Existen diversas acepciones de la palabra "constitución". GUASTINI identifica, al menos, cuatro. Una primera aproximación como sinónimo de Estado liberal; luego indica que la constitución denota un grupo de normas jurídicas que le dan ciertas características a todo el ordenamiento; una tercera acepción es puramente documental, pues una constitución es el documento que lleva ese nombre; y finalmente, para él una constitución es un documento jurídico que tiene ciertas características formales ${ }^{21}$. FERREYRA define constitución como "una combinación de normas jurídicas que regulan y determinan el modo en que debe ser ejercido y controlado todo el poder político y, paralelamente, por las que se confiere el reconocimiento a los derechos fundamentales de los habitantes". De acuerdo al autor, sus finalidades esenciales son: "proteger y satisfacer los derechos de libertad, los derechos sociales y los derechos de tercera generación"; y "estipular los procedimientos que aseguren un ejercicio racional y controlado de los poderes del Estado"22,

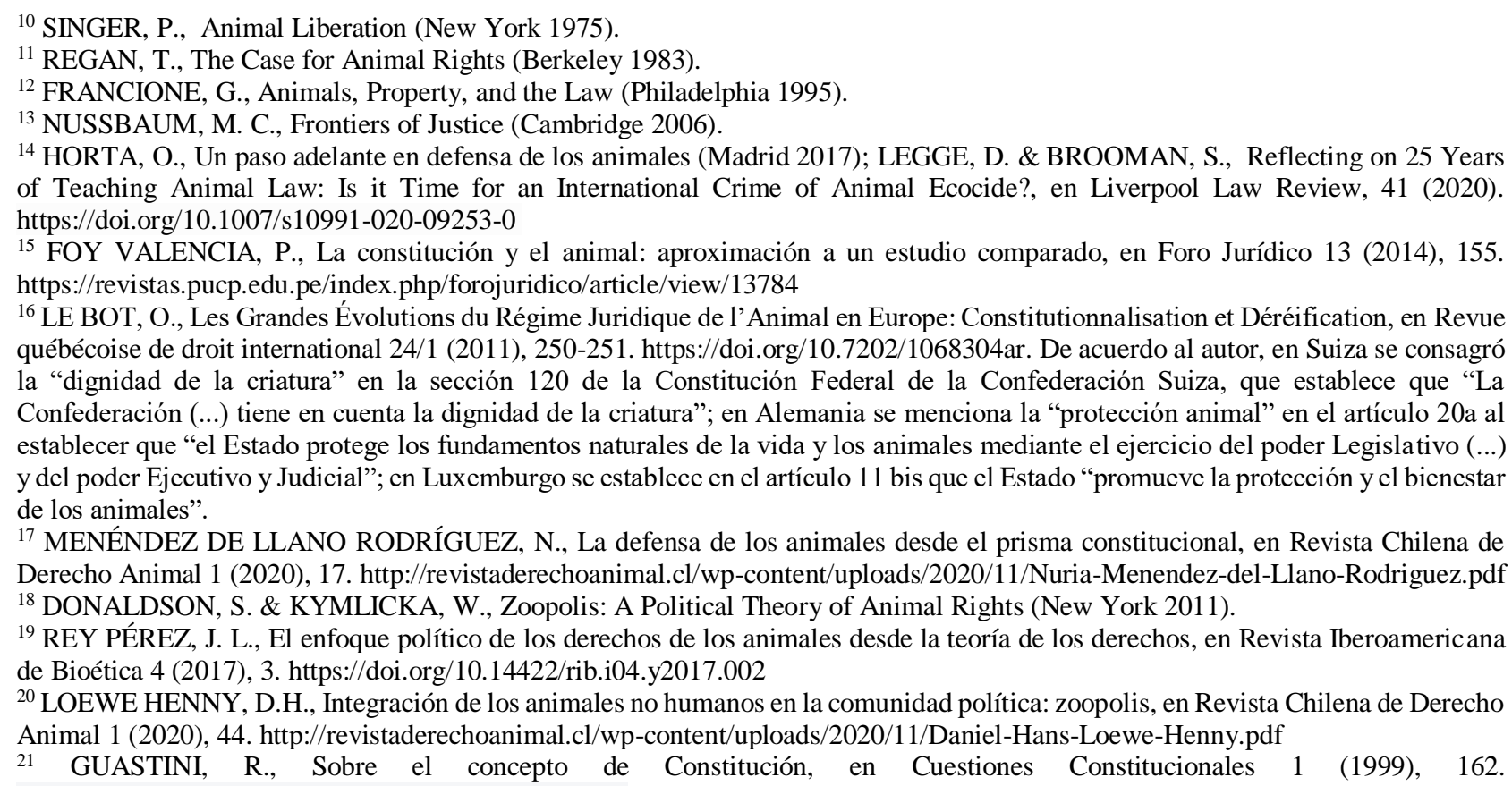
http://dx.doi.org/10.22201/iij.24484881e.1999.1.5566

${ }^{22}$ Op. cit. FERREYRA (2013b) 348. 
convirtiéndose en un elemento central de la sociedad.

Las constituciones tienen ciertos contenidos mínimos, siendo algunos de ellos las normas que establecen las relaciones entre el Estado y las y los ciudadanos, y normas que expresan los valores y principios que forman parte de la sociedad ${ }^{23}$. Además, las constituciones son avaladas por el principio de supremacía constitucional, que implica la superioridad de la constitución, impidiendo su reforma, sin seguir procesos agravados, y contando con garantías jurisdiccionales en caso de vulneración de su contenido por otras normas ${ }^{24}$.

Así entendidas, las constituciones son el máximo instrumento de ordenación del quehacer comunitario $^{25}$, y su finalidad es servir al desarrollo de la vida de los individuos de la comunidad ${ }^{26}$. Pero ¿a qué individuos se refiere? ¿Quiénes forman parte de la comunidad? Objetivamente, es imposible desconocer que los demás animales habitan en los territorios estatales, viven en las ciudades, y hasta en nuestros hogares, a quienes incluso consideramos parte de nuestras familias ${ }^{27}$.

Pero lo cierto es que desde los tiempos de Roma un ente podía ser considerado como una persona o una cosa. Mientras las personas son las únicas que pueden ser titulares de derechos, las cosas no tienen ningún tipo de derecho, e incluso sus intereses más fundamentales carecen de protección ${ }^{28}$. Históricamente, los demás animales han sido ubicados en este segundo grupo, una herencia del Derecho Romano que se ha perpetuado, y cuya explicación estaría dada por la falta de un verdadero debate social y la ausencia de una urgencia política $^{29}$.

No es extraño que, como el mismo FERREYRA reconoce, para el mundo jurídico constitucional el ser humano es el centro del universo, y ante ello "la conclusión es lacónica: antropocentrismo constitucional" ${ }^{30}$. Es así como, por ejemplo, los humanos han concebido la ciudadanía como algo que tiene que ver sólo con ellos mismos, limitándola por tradición, a singulares y restringidos grupos, sobre bases políticas y territoriales ${ }^{31}$. Por ejemplo, "[1]a idea romana de ciudadanía hace referencia a un status integrado por un núcleo compacto e indesmembrable de derechos y deberes que definían la posición de las personas libres en la República" ${ }^{32}$ o la idea de la ilustración de ciudadanía propuesta por Diderot y D'Alambert que resalta que "[1]a ciudadanía es una condición de la persona que vive en una sociedad libre" ${ }^{\text {"3 }}$.

Como explican DONALDSON \& KYMLICKA, en la teoría política tradicional, el ciudadano ha sido concebido como una persona con capacidades para la razón pública, logos, autonomía kantiana, o reflexión y deliberación racionales ${ }^{34}$. Estas características, junto con el lenguaje, situarían al ser humano en una posición de superioridad ${ }^{35}$. Sin embargo, las recientes luchas ciudadanas ofrecen una concepción muy diferente de la base y propósito de la ciudadanía, fundada no en la posesión de las capacidades señaladas, sino en los derechos de pertenencia y participación en una sociedad de iguales ${ }^{36}$.

Comprendida de esta manera, la ciudadanía sería una forma de reconocer quién pertenece aquí, quién es miembro del pueblo en cuyo nombre gobierna el Estado y cuyo bien subjetivo debe ser considerado en la determinación del interés público ${ }^{37}$. Bajo esta mirada, sería posible atender a las distintas formas en que los demás animales se relacionan con las instituciones políticas y las prácticas de soberanía del Estado, territorio, colonización, migración y pertenencia ${ }^{38}$. Así, "incluir la animalidad en el espacio público es incluir la

\footnotetext{
${ }^{23}$ Op. cit. GUASTINI (1999) 164-165.

${ }^{24}$ PRIETO SANCHÍS, L., El constitucionalismo de los derechos: Ensayos de filosofía jurídica (Madrid 2013), 160.

${ }^{25}$ Op. cit. FERREYRA (2018) 78.

${ }^{26}$ Op. cit. FERREYRA (2013a) 53.

27 FARACO, C., Interação humano-animal, en Ciência Veterinária nos Trópicos, 11 (2008). https://www.bvsvet.org.br/vetindex/periodicos/ciencia-veterinaria-nos-tropicos/11-(2008)/interacao-humano-animal/; GONZÁLEZ MARINO, I., El fenómeno de las familias multiespecie y los desafíos que supone para el Derecho, en Personalidad jurídica de los animales no humanos y nuevas tendencias en Derecho animal (Santiago 2019).

${ }^{28}$ WISE, S., Sacudiendo la jaula: hacia los derechos de los animales (Valencia 2018), 13.

${ }^{29}$ GIMÉNEZ-CANDELA, T., Introducción, en Animales y Derecho (Valencia 2015), 12.

${ }^{30}$ Op. cit. FERREYRA (2013a) 306.

${ }^{31}$ POCAR, V., Los animales no humanos: por una sociología de los derechos (Buenos Aires 2013), 148.

32 PÉREZ LUÑO, A. E., Ciudadanía y definiciones, en Doxa: Cuadernos de Filosofía del Derecho 25 (2002), 183. https://doi.org/10.14198/DOXA2002.25.05

${ }^{33}$ Op. cit. PÉREZ LUÑO (2002) 185.

34 DONALDSON, S., \& KYMLICKA, W., Rethinking Membership and Participation in an Inclusive Democracy: Cognitive Disability, Children, Animals, en Disability and Political Theory (Cambridge 2016). https://doi.org/10.1017/9781316694053.009

${ }^{35}$ BLUE, G., \& ROCK, M., Animal publics: accounting for heterogeneity in political life, en Society \& Animals 22/5 (2014), 505. https://doi.org/10.1163/15685306-12341350

${ }^{36}$ Op. cit. DONALDSON \& KYMLICKA (2016) 234.

${ }^{37}$ Ibíd., 235.

${ }^{38}$ DONALDSON, S. \& KYMLICKA W., Zoópolis, una revolución animalista (Madrid 2018) 441.
} 
diversidad y la heterogeneidad de las distintas maneras de conectarse entre especies" 39 .

Es así como DONALDSON \& KYMLICKA diferencian tres grupos de animales no humanos: domésticos, salvajes y liminales, no en función de la especie, sino las relaciones "políticas" que mantienen con los humanos. Los domésticos serían aquellos que forman parte de nuestra comunidad política en calidad de co-ciudadanos. Los salvajes no tendrían interés en formar parte de nuestra comunidad, pero indiscutiblemente nuestras acciones sobre el ecosistema les afectan, por lo que habrá que respetar su ámbito de "soberanía". Finalmente, los liminales, aquellos que viven en nuestras ciudades pero no como animales domésticos, serían cuasi-ciudadanos, pues se encontrarían en una situación fronteriza al convivir con nosotros, aunque desinteresados en formar parte de la sociedad ${ }^{40}$.

En suma, para DONALDSON \& KYMLICKA, en lugar de cortar las relaciones entre humanos y demás animales, se debe explorar y aprovechar las posibilidades de estas relaciones. Ello implica reconocerlos no sólo como sujetos individuales cuyos derechos básicos han de respetarse, sino como miembros de comunidades -tanto las nuestras como las suyas- entrelazadas en relaciones de interdependencia, mutualidad y responsabilidad ${ }^{41}$. Esto daría lugar a "los cimientos de una futura zoópolis" ${ }^{2}$, cuestión que se plantea como una verdadera necesidad en el mundo actual.

\section{Comunidad más allá de la ciudadanía y la especie}

El ciudadano es el sujeto central en la organización estatal. Y siguiendo a FERREYRA, la asociación de ciudadanos consiste en la concurrencia a un contrato. Por ello, constitución y contrato son palabras equivalentes, pues son la forma de organización pactada por intermedio de la libertad de las y los ciudadanos. Libertad que, como veremos, no todos disponen ni pueden ejercer por igual ${ }^{43}$.

La fuente de este contrato político reside en el poder de las y los ciudadanos que integran el pueblo ${ }^{44}$. Así, la constitución es el resultado de un proceso político: la autodeterminación comunitaria ${ }^{45}$. Sin embargo, llegados a este punto, las interrogantes del apartado precedente cobran aún más importancia, pues el concepto de comunidad aquí empleado parece ser incluso más restrictivo que aquel limitado a la especie humana. Indudablemente, no todos los seres humanos de una comunidad tienen la calidad de ciudadanos.

Por lo anterior, surge aquí la cuestión de si el acento debe estar puesto sobre quienes crean y suscriben el contrato político -ciudadanos y ciudadanas-, o sobre quienes son sus destinatarios y destinatarias -todos los miembros de la comunidad-. En este punto seguimos a FERRAJOLI, para quien una constitución es democrática, más allá de la voluntad mayoritaria, no tanto porque es voluntad de todos, sino porque garantiza a todos; no porque los derechos en ella establecidos sean universalmente aceptados, sino porque se confieren universalmente a todos; no porque nadie esté excluido de su estipulación, sino porque en ella se pacta la no exclusión de nadie ${ }^{46}$. En este sentido, la democracia se entrelaza con un espacio público que está abierto a la inclusión no solo de personas o animales humanos, sino que se transforma discursivamente y materialmente a un conjunto de cuerpos, prácticas y tecnologías que disrumpe la institucionalidad vigente ${ }^{47}$.

FERRAJOLI aboga por una perspectiva garantista de las constituciones, entendidas como pactos de convivencia, tanto más necesarios y preciosos cuanto más profundas son las diferencias personales que están llamadas a tutelar, cuanto más heterogéneas y conflictivas son las subjetividades políticas cuya convivencia deben garantizar, y cuanto más vistosas e intolerables son las desigualdades materiales que tienen la tarea de remover o reducir. Así concebidas, las constituciones sirven para garantizar los derechos de todos, incluso contra la mayoría, para asegurar la convivencia pacífica entre sujetos e intereses diversos, virtualmente en conflicto. "Son, por así decirlo, pactos de no agresión y de mutuo apoyo, cuya razón social es la garantía de la paz y de los derechos vitales de todos, tanto más esenciales cuanto mayores son los peligros de guerra y de dominación" ${ }^{48}$, convirtiendo a la constitución en sí misma en una garantía para todos quienes materialmente forman parte de la comunidad.

\footnotetext{
39 BECERRA VALDIVIA, K., Competencias ciudadanas y animales no humanos: descentralizando el sujeto político, creando competencias ensambladas-ciudadanas, en Derecho Animal, tenencia responsable y otras propuestas interdisciplinarias (Santiago 2021), 312.

40 Op. cit. REY PÉREZ (2017) 9.

${ }^{41}$ Op. cit. DONALDSON \& KYMLICKA (2018) 446.

${ }^{42}$ Ibíd., 448.

${ }^{43}$ Op. cit. FERREYRA (2013b) 376.

${ }^{44}$ Op. cit. FERREYRA (2013a) 271.

${ }^{45}$ Ibíd., 53.

${ }^{46}$ FERRAJOLI, L., Principia iuris. Teoría del derecho y de la democracia: 2. Teoría de la democracia (Madrid 2013b), 55.

${ }^{47}$ Op. cit. BLUE \& ROCK (2014) 515.

${ }^{48}$ Op. cit. FERRAJOLI (2013b) 54-55.
} 
Bajo esta lógica, en palabras de FERRAJOLI: "Todo el Derecho, en realidad, es ley del más débil, y como tal ha ido avanzando siempre". Explica el autor que cada conquista de derechos y cada progreso en la igualdad y garantías de la persona se han producido siempre como consecuencia de la revelación de una discriminación o de una opresión de sujetos débiles o diferentes, reputada en cierto punto intolerable gracias a luchas y reivindicaciones ${ }^{49}$. De esta manera, nada impide que las clases de personas naturales o sujetos jurídicos sean más o menos amplias: en un ordenamiento esclavista, por ejemplo, algunos humanos son cosas y no personas; y a la inversa, es perfectamente posible que en un ordenamiento les confiera a los demás animales -o a algunos- el estatus de persona o, por lo menos, de sujetos jurídicos en cuanto titulares de derechos $^{50}$. En este sentido, el Derecho, como creación humana, evoluciona en los diversos contextos históricos y sociales.

Bajo una perspectiva así -inclusiva, garantista y que supere la discriminación por especie o especismo, y siguiendo a NUSSBAUM, podríamos considerar perfectamente plausible la idea de un pacto social que incluyera también a los demás animales ${ }^{51}$. En estos términos -indica la autora- "una justicia verdaderamente global no requiere simplemente que miremos al otro lado del mundo en busca de otros congéneres con derecho a una vida digna. También nos exige mirar (...) a esos otros seres sensibles con cuyas vidas tan inextricable y complejamente entrelazadas están las nuestras" ${ }^{\prime 2}$.

Esto, por cierto, encierra enormes desafíos. Como indica REY PÉREZ (2017), reconocer a los demás animales como miembros de nuestras comunidades políticas implica que habrá que juridificar relaciones, reconocerles derechos, hacernos sujetos de obligaciones y regular las formas de vida en común y de cooperación ${ }^{53}$. Implica reconocer una realidad: que son parte de nuestras comunidades, que viven en los que hemos denominado "nuestros" estados, ciudades, y hogares; y como tales, el máximo instrumento de ordenación comunitaria -la constitución-, no puede excluirlos sin que ello constituya una decisión arbitraria, más aún si la constitución tiene un importante rol en preservar la paz en la comunidad política.

\section{La constitucionalización de la protección de los demás animales}

Hace un par de décadas los animales no humanos aparecían en el Derecho Constitucional únicamente a través del concepto de medioambiente y los principios que se relacionan con él. Esto ha sido así pues, para proteger a los humanos, se suele resguardar al medioambiente y, a veces, a los demás animales. En consecuencia, los animales no humanos aparecían sólo indirectamente como objeto de Derecho Constitucional $^{54}$.

De acuerdo a diversos textos constitucionales, los demás animales han sido tratados como recursos naturales, criaturas, especies, poblaciones, ejemplares, individuos, organismos, comunidades, fauna, entre otros $^{55}$. Pero cualquiera sea la categoría jurídica adoptada para proteger la vida animal, lo cierto es que en varios países la cuestión ya toca las esferas constitucionales ${ }^{56}$.

LE BOT $^{57}$ explica que las razones del fenómeno de constitucionalización del Derecho Animal están asociadas a consideraciones éticas y filosóficas que tienen en cuenta la sintiencia de los demás animales. Pero a ello -indica- se suman razones de técnica legislativa. Las disposiciones de protección animal situadas a nivel legal ceden ante los derechos fundamentales consagrados a nivel constitucional. Se trata de dos estándares de valor desigual, donde siempre prevalece el de mayor jerarquía. Muestra de lo anterior son los casos en que la consagración meramente legal de la protección a los demás animales queda anulada por la libertad artística, la libertad de investigación científica, la libertad de educación o la libertad de desarrollar actividades económicas, entre tantos otros derechos. Por ello, la legislación de protección animal se vuelve ineficaz cuando entra en conflicto con un derecho fundamental. Esto es claro al revisar el caso de Alemania. Como consta en la exposición de motivos del Proyecto de Ley de reforma constitucional del artículo 20a de la Ley Fundamental de la República Federal Alemana, una de las primeras en hacerse cargo de la problemática

\footnotetext{
${ }^{49}$ Op. cit. FERRAJOLI (2004) 103-104.

${ }^{50}$ FERRAJOLI, L., Principia iuris. Teoría del derecho y de la democracia: 1. Teoría del derecho (Madrid 2013a), 332.

${ }^{51}$ NUSSBAUM, M. C., Las fronteras de la justicia (Barcelona 2016), 328.

52 Ibíd., 399.

${ }^{53}$ Op. cit. REY PÉREZ (2017) 8.

${ }^{54}$ GASSIOT, O., L'animal, nouvel objet du droit constitutionnel, en Revue française de droit constitutionnel, 4/4 (2005), $703-732$. https://doi.org/10.3917/rfdc.064.0703

55 NAVA ESCUDERO, C., Los animales como sujetos de derecho, en dA. Derecho Animal (Forum of Animal Law Studies) 10/3 (2019). https://doi.org/10.5565/rev/da.444

56 PAUCAR ESPINOZA, M., Protección animal: una reflexión constitucional, en Desde el Sur 5/1 (2012), 15-23. https://biblat.unam.mx/hevila/DesdeelsurLima/2012-2013/vol5/no1/1.pdf

${ }^{57}$ Op. cit. LE BOT (2011).
} 
animal a nivel constitucional ${ }^{58}$ :

“(...) a la protección ética de los animales se le atribuye hoy un alto valor. Las decisiones de varios Tribunales permiten reconocer la tendencia jurisprudencial de tener en cuenta este cambio de conciencia en la interpretación de la Constitución. Esto, sin embargo, solo puede ser realizado adecuadamente por la Jurisdicción si se incluye expresamente la protección de los animales en la estructura de la Ley Fundamental" ${ }^{159}$.

Para LE BOT, la presencia de los animales no humanos en el texto de mayor jerarquía del ordenamiento jurídico refleja un cambio de importancia. Significa que las reglas que rigen la relación entre el ser humano y los demás animales ya no deben ser abandonadas al legislador ${ }^{60}$. Esto cobra especial relevancia al considerar el surgimiento y consolidación de principios constitucionales orientados a la protección de los animales no humanos. Por ejemplo, gracias al artículo 13 del Tratado de Funcionamiento de la Unión Europea ${ }^{61}$, se ha establecido que el bienestar de los demás animales, como seres sintientes, es un principio general de Derecho Europeo, de rango constitucional ${ }^{62}$. En México, en tanto, la Suprema Corte de Justicia de la Nación ${ }^{63}$ ha establecido que el bienestar animal es un principio constitucional implícito que puede limitar de manera legítima derechos fundamentales y humanos ${ }^{64}$. Así, el surgimiento de principios y normas constitucionales destinadas a dar protección a los demás animales implica que los intereses de los humanos no pueden, a priori, valer o importar más que los de individuos de otras especies y, en todo caso, las colisiones tendrán que ser resueltas bajo criterios de racionalidad; no de fuerza, poder o hegemonía. Esto es posible, en la medida que dejemos de considerar al Derecho y los derechos como mera manifestación de la ley del más fuerte y, al contrario, sean concebidos como ley del más débil.

En definitiva, la creciente presencia de los demás animales en la vida contemporánea y su consecuente impacto en los sistemas jurídicos, requiere de un enfoque integral y sistémico ${ }^{65}$. En este sentido, PEZZETTA apunta la necesidad de desarrollos teóricos que aborden, entre otras cuestiones, qué teoría constitucional necesitamos para dar cuenta cabalmente de que nuestras sociedades son multiespecies ${ }^{66}$. Esto último es fundamental, pues el solo rango constitucional de la protección otorgada a los demás animales no es garantía absoluta de mejora de su situación, aun cuando la mayoría de los estudios ven efectos concretos o simbólicos positivos.

Por ejemplo, un estudio acerca del impacto de la protección constitucional de los animales no humanos en el artículo 20a de la Constitución alemana, efectuado a partir de un análisis de la jurisprudencia, reveló que no se ha producido un cambio significativo de paradigma y que los cambios han sido marginales. En efecto, se estableció que, en este caso particular, el potencial para limitar derechos fundamentales de los humanos es restringido. A pesar de ello, se demostró que el bienestar animal se incluyó de manera más intencional y explícita en la toma de decisiones y el equilibrio de intereses, por lo que la disposición constitucional ha tenido un sentido protector ${ }^{67}$. Otro trabajo en el que se analizan las protecciones constitucionales otorgadas a los demás animales en Suiza, Alemania, Brasil e India, afirma que casi todas se han interpretado a través de un enfoque antropocéntrico, por lo que han tenido un impacto limitado y más bien simbólico ${ }^{68}$.

\footnotetext{
${ }^{58}$ DOMÉNECH PASCUAL, G., Colisiones entre bienestar animal y derechos fundamentales, en El derecho de los animales (Madrid 2015).

${ }^{59}$ Ibíd., 102.

${ }^{60}$ Op. cit. LE BOT (2011).

${ }^{61}$ Que dispone: “Al formular y aplicar las políticas de la Unión en materia de agricultura, pesca, transporte, mercado interior, investigación y desarrollo tecnológico y espacio, la Unión y los Estados miembros tendrán plenamente en cuenta las exigencias en materia de bienestar de los animales como seres sensibles, respetando al mismo tiempo las disposiciones legales o administrativas y las costumbres de los Estados miembros relativas, en particular, a ritos religiosos, tradiciones culturales y patrimonio regi onal".

${ }^{62}$ ALONSO, E., El artículo 13 del Tratado de Funcionamiento de la Unión Europea: Los animales como seres "sensibles [sentientes]" a la luz de la jurisprudencia del Tribunal de Justicia de la Unión Europea, en Animales y Derecho (Valencia 2015).

${ }^{63}$ SUPREMA CORTE DE JUSTICIA DE LA NACIÓN (SCJN), MÉXICO. 31 de octubre de 2019. Amparo en revisión 163/2018. Quejosos: Comisión mexicana de promoción gallística, asociación civil y Efraín Rábago Echegoyen. https://bj.scjn.gob.mx/doc/sentencias_pub/dyVS3XgB_UqKst8os7a9/\%22Combatientes\%22\%20

${ }^{64}$ DE LA TORRE TORRES, R. M., El bienestar animal como principio constitucional implícito y como límite proporcional y justificado a los derechos fundamentales en la Constitución mexicana, en dA. Derecho Animal (Forum of Animal Law Studies) 11/3 (2020). https://doi.org/10.5565/rev/da.506

${ }^{65}$ Op. cit. FOY VALENCIA (2014) 20.

${ }^{66}$ PEZZETTA, S., El giro animal: impacto y desafíos para el derecho latinoamericano, en Revista Chilena de Derecho Animal 1 (2020), 34. http://revistaderechoanimal.cl/wp-content/uploads/2020/11/Silvina-Pezzetta-1.pdf

${ }^{67}$ VERNIERS, E., The impact of including animals in the constitution - Lessons learned from the German animal welfare state objective, en Global Journal of Animal Law 8 (2020). https://ojs.abo.fi/ojs/index.php/gjal/article/view/1691

${ }^{68}$ DECKHA, M., Constitutional protections for animals: A comparative animal-centred and postcolonial reading, en Colonialism and
} 
Una interpretación más positiva de las cláusulas constitucionales relativas a la protección animal, que incluye a los países ya mencionados -además de Luxemburgo, Austria y Egipto-, asevera que estas normas no son meras declaraciones de principios, y que representan normas jurídicas efectivas que producen efectos concretos en el sistema jurídico. Así, ello se traduciría en la obligación de las autoridades públicas de hacer efectivas las normas y limitar los derechos fundamentales de las personas en orden a otorgar mayor protección a los demás animales ${ }^{69}$.

Otras interpretaciones menos optimistas del efecto de las disposiciones constitucionales de protección animal, como el de un estudio que revisa el caso de Israel, afirman que consagrar derechos a los animales en las constituciones ha sido incluso contraproducente, basado en la doctrina de la proporcionalidad para resolver conflictos entre derechos ${ }^{70}$. Al usar esta doctrina -se ha dicho-, se sigue permitiendo que la industria agrícola pueda causar sufrimiento a animales no humanos para obtener bienes que se consideran básicos por la sociedad $^{71}$. Sin embargo, los autores -al mismo tiempo- reconocen que se puede lograr cierto grado de protección más eficiente al usar principios constitucionales que pueden homologarse para ser usados respecto de los demás animales ${ }^{72}$. Como se aprecia, el contenido, alcance y enfoque de las disposiciones constitucionales que brinden protección a los animales no humanos son un elemento clave en la efectividad de su aplicación y la consecuente mejora de las condiciones de vida de estos individuos. En tal sentido, la paz, como fin del Derecho, puede ayudar a orientar esta tarea.

\section{Propuesta: la Paz como uno de los fundamentos de protección constitucional de los demás animales}

La doctrina en materia de Ética y Derecho Animal ha ofrecido importantes y sólidos argumentos para descosificar $^{73}$ y dar mayor protección a los demás animales ${ }^{74}$, incluso a nivel constitucional ${ }^{75}$. Los fundamentos de tales planteamientos se han articulado usualmente a partir de conceptos como igualdad, no discriminación, justicia y solidaridad ${ }^{76}$. En este trabajo se propone que si los demás animales son parte de las comunidades democráticas, su inclusión en la constitución viene dada por alcanzar la paz como un fin del Derecho, que obliga a concentrar el uso de la fuerza en el Estado, sacando esta atribución de los particulares y, por cierto, abstrayéndose de ser usada contra los animales no humanos, como se hace en la actualidad. Esto se explicará a continuación, primeramente, aclarando conceptualmente qué se entiende por paz como fin del Derecho, y luego explicando la concatenación de los conceptos de paz, animales no humanos y constitución.

\subsection{La Paz como fin del Derecho}

Un valor al interior de nuestras comunidades democráticas que puede facilitar el proceso de juridificación de la protección de los demás animales en las constituciones es el de la paz, entendida como un fin último del Derecho. La paz es nombrada como uno de los fines del Derecho, junto con la seguridad jurídica,

Animality (London 2020). https://doi.org/10.4324/9781003013891

${ }^{69}$ LE BOT, O., Is it useful to have an animal protection in the constitution?, en US-China Law Review 15/1 (2018). DOI:10.17265/1548-6605/2018.01.004

${ }^{70}$ BENDOR, A. L., \& DANCING-ROSENBERG, H., Animals rights in the shadow of the constitution, en Animal Law 24/1 (2018). https://law.lclark.edu/live/files/32155-24-1-shadowpdf

${ }^{71}$ Ibíd, p. 134.

${ }^{72}$ Ibíd, p. 135.

${ }^{73}$ FRANCIONE, G., Animals as Persons: essays on the abolition of animal exploitation (New York 2008); op. cit. FRANCIONE (1995); op. cit. REGAN (1983); GIMÉNEZ-CANDELA, T., Transición animal en España (Valencia 2020); op. cit. POCAR (2013), entre otros y otras.

${ }^{74}$ Op. cit. SINGER (1975); op. cit. Nussbaum (2006); WOLF, U., Ética de la relación entre humanos y animales (Madrid 2014); RACHELS, J., The elements of moral philosophy (New York 2003), entre otros y otras.

75 Op. cit. LE BOT (2011); op. cit. GASSIOT (2005); EISEN, J., Animals in the constitutional state, en International Journal of Constitutional Law 15/4 (2018) 909. https://doi.org/10.1093/icon/mox088; op. cit. FOY VALENCIA (2014); op. cit. PAUCAR ESPINOZA (2012); op. cit. MENÉNDEZ DEL LLANO RODRÍGUEZ (2020), entre otros y otras.

76 Véase: PEZZETTA, S., Derechos fundamentales para los demás animales. Especismo, igualdad y justicia interespecies, en Lecciones y Ensayos 100 (2018). http://www.derecho.uba.ar/publicaciones/lye/revistas/100/derechos-fundamentales-para-los-demasanimales.pdf; DE LA TORRE TORRES, R. M., Los fundamentos de los derechos de los animales (Ciudad de México 2021); PEZZETTA, S., Una teoría del derecho para los animales no humanos. Aportes para la perspectiva interna del Derecho, en Revista de Bioética y Derecho 44 (2018). https://doi.org/10.1344/rbd2018.0.20896; REY PÉREZ, J. L., los derechos de los animales en serio (Madrid 2018); op. cit. WISE (2018); COULTER, K., Animals, work, and the promise of interspecies solidarity (New York 2016); VALENCIA RINCÓN, F., Derechos animales, solidaridad y derechos emergentes, en Icase. Revista de la Facultad de Derecho 109 (2020). http://dx.doi.org/10.14422/icade.i109.y2020.005; GONZÁLEZ MARINO, I., Hacia un principio de solidaridad ecológica e interespecies, en Revista Chilena de Derecho Animal 1 (2020). http://revistaderechoanimal.cl/wp-content/uploads/2020/11/IsraelGonzalez-Marino.pdf 
la justicia y el bien común ${ }^{77}$. Incluso, para algunos es una consecuencia del bien común ${ }^{78}$, entendido como una situación en que cada miembro de la sociedad alcanza su mayor potencial material y espiritual posible. La paz ha sido un concepto difícil de definir. Algunos dicen que es imposible por su gran carga política ${ }^{79}$, aun así, a lo largo de la historia muchos autores lo han intentado. KELSEN, por ejemplo, dice que la paz es un estado caracterizado por la ausencia del uso de la fuerza ${ }^{80}$. Desde las guerras mundiales, se ha remarcado la paz como un estado de no guerra ${ }^{81}$, siendo un concepto muy usado en el Derecho Internacional. Pero la paz, como un fin del Derecho, es mucho más que eso.

Que la paz sea un fin del Derecho significa que el ordenamiento jurídico debe tender a establecer ciertos objetivos que faciliten la vida en comunidad. En palabras de SQUELLA NARDUCCI, el Derecho, al "monopolizar con éxito el uso de la fuerza, termina la guerra de todos contra todos e impide que las luchas y conflictos de intereses entre individuos y grupos concluya simplemente con la aplicación de la ley del más fuerte" ${ }^{\prime 2}$. Esta idea se encuentra desarrollada en otro texto, al señalar que "Si el derecho no se atribuyera el monopolio del uso de la fuerza, centralizando su ejercicio a través de órganos jurisdiccionales y coactivos independientes, entonces sí que lo más probable sería que el devenir de las relaciones sociales quedara librado a lo que usualmente se llama «la ley del más fuerte»" ${ }^{83}$. En otras palabras, en un estado de paz, hay un uso de la fuerza racional y centralizado en algunos individuos que están autorizados a su uso solo en caso de tener que sancionar alguna conducta delictiva ${ }^{84}$. Es por esto que se señala que hay una fuerza prohibida, la que un individuo ejerce impropiamente sobre otros u otros; y otra permitida, que es la que el Derecho puede usar en una comunidad, a través de órganos estatales ${ }^{85}$. Por esto se habla que la paz que se puede lograr en una sociedad es relativa, pues siempre habrán hechos de fuerza que se realicen al margen del Derecho y porque el Derecho puede usarla legítimamente ${ }^{86}$.

Todo lo anterior lleva a pensar en el rol de la paz en nuestra vida diaria, más allá de los conflictos armados o de la autorización estatal del uso de la fuerza, pues de acuerdo con ARANGO DURLING, citando a Bedjaoui, la paz debe definirse también como "la ausencia de toda violencia estructural causada por la negación de las libertades fundamentales y por el subdesarrollo económico y social" violencia, conflicto, conmoción o alteración al estado de tranquilidad y armonía puede considerarse como la antítesis de la paz"88, lo que sin duda hace reflexionar sobre la justificación de ciertas violencias estructurales o conflictos, permitidos y avalados en sociedad incluso por el Derecho, y que afectan a miembros no humanos de la comunidad democrática.

Estos conceptos de paz llevan a preguntarnos por qué contra los animales no humanos, que son parte de la comunidad como se ha establecido anteriormente, se puede hacer uso indiscriminado de la fuerza, siendo víctimas de la violencia estructural creada por los humanos, que están en una posición de ser "los más fuertes" en la relación. De esta manera, los demás animales, como parte de la comunidad, también requieren ser incluidos en la constitución, con el objeto de que efectivamente puedan gozar de esta situación de libertad de fuerza indiscriminada, cambiando las obligaciones del Estado y los particulares, siendo protegidos como los más débiles, siguiendo a FERRAJOLI, en la relación de poder.

\subsection{Paz, animales no humanos y constitución}

La paz, como fin del Derecho, nos invita a pensar las relaciones de los miembros de la comunidad libre de toda fuerza ejercida por un otro. Esto pone de manifiesto la necesidad de que nuestras relaciones se basen en contextos no violentos. Si los otros animales son parte de esta comunidad democrática, como sujetos políticos y jurídicos, su inclusión en el texto constitucional es obvia.

Si el texto constitucional se establece como un instrumento para ordenar la vida en comunidad y servir al desarrollo de la vida de sus integrantes, los animales no humanos deben estar incluidos por ser parte de esta

\footnotetext{
77 Op. cit. SQUELLA NARDUCCI (2014) 634; GAETE ROJAS, S., Los Fines del Derecho, en Revista Chilena de Derecho 2 (1975) 81. https://dialnet.unirioja.es/servlet/articulo?codigo $=2649248$

${ }^{78}$ Op. cit. GAETE ROJAS (1975) 81.

${ }^{79}$ MERCADO PÉREZ, D., La imposibilidad de definir el concepto de paz en el derecho, en Academia \& Derecho 15 (2018) 111. https://doi.org/10.18041/2215-8944/academia.15.4334

${ }^{80}$ KELSEN, H., Peace through law (New Jersey 2000) 3.

81 Op. cit MERCADO PÉREZ (2018) 111; ARANGO DURLING, V., Paz social y cultura de paz (Panamá 2007) 15.

${ }^{82}$ Op. cit. SQUELLA NARDUCCI (2014) 636.

${ }^{83}$ SQUELLA NARDUCCI, A., El Derecho y la fuerza, en Doxa 15-16 (1994), 812. https://doi.org/10.14198/DOXA1994.15-16.40

${ }^{84}$ Op. cit. KELSEN (2000) 3.

${ }^{85}$ Op. cit. SQUELLA NARDUCCI (2014) 635.

${ }^{86}$ Ibíd., 636.

${ }^{87}$ Op. cit. ARANGO DURLING (2017) 15.

88 SUÁREZ, K. S., El Derecho a la paz y el derecho al servicio de la paz, en Revista Jurídica 32 (2018), 106. https://www.revistajuridicaonline.com/wp-content/uploads/2021/05/32-7-EL-DERECHO-A-LA-PAZ.pdf
} 
comunidad, y de esa manera se sustraen de situaciones de fuerza contra ellos establecidas por los propios seres humanos. Si la paz busca alcanzar situaciones en las cuales no exista la fuerza, no está de más que la misma constitución establezca, a lo menos, ciertos ámbitos de protección o derechos para aquellos miembros de la sociedad que se encuentran en clara desventaja. Las consecuencias de esta inclusión en el ámbito jurídico son inmensas y se desenvuelven en un terreno de nuevas obligaciones para el Estado y un cambio en las relaciones de poder de los particulares hacia los demás animales.

La primera consecuencia es el cambio en los límites del Estado respecto al uso de la fuerza sobre los animales no humanos. Si el Estado es el único que puede concentrar su uso, habría que señalar cuáles serían los casos legítimos para que se pudiese usar la fuerza contra los animales no humanos. Si en el caso de los animales humanos esta justificación sólo se da en los delitos, en los no humanos se tiene que tener en cuenta su animalidad y las capacidades que estos presentan, tal como se hace con personas inimputables. Del mismo modo, no se ven buenas razones para que el Estado pueda usar la fuerza en otros casos distintos a los contemplados para los humanos. Esto representa un estándar ético de protección del Derecho, que tiene especial consideración por aquellos miembros más vulnerables en una comunidad.

Desde el análisis de la inclusión de la protección constitucional de los animales no humanos en varios países, EISEN argumenta que debe existir una teoría constitucional suplementaria, que no solo se base en la dignidad y la autoafirmación democrática de los seres humanos como su centro. En su lugar, propone que la obligación de los Estados se basa en atender los intereses de los miembros que más lo necesitan, los más vulnerables, como los demás animales, especialmente cuando estos miembros son incapaces de esta autoafirmación democrática ${ }^{89}$. Por lo anterior, la legislación referente al maltrato de los animales no humanos debe modificarse, equiparando sus sanciones a las de los delitos cometidos contra humanos, pues como miembros de la comunidad democrática, se encuentran en igual necesidad de ser protegidos de la fuerza que otro miembro de la sociedad pueda ejercer en su contra. Lo anterior obliga al Estado a repensar el bien jurídico protegido en estos casos, para que efectivamente se pueda vivenciar la paz entre los sujetos.

Otra consecuencia, que deriva de la primera, es un cambio en la legislación sobre el tratamiento de los animales no humanos en diversas industrias, como la alimentaria y la cosmética, solo por nombrar algunas. En estas industrias se refleja una relación de poder de los particulares hacia los animales no humanos. Si el Estado sólo utilizará la fuerza en caso de delito, el uso de la fuerza que los particulares ejercen sobre los animales también debe revisarse y limitarse a su mínima expresión. Dichas legislaciones sectoriales específicas deberán limitar o eliminar, según el caso, la fuerza que es ejercida hacia los animales no humanos, de modo de alinearse a la paz como fin del Derecho. Así, la obligación de protección del Estado y de otros miembros de la sociedad, obliga a mayores y mejores estándares de protección.

En el ámbito doméstico, será también necesario revisar el poder que se ejerce sobre los animales no humanos con los que usualmente convivimos, cuyo ejercicio se encuentra actualmente amparado por el Estado. En efecto, algunas investigaciones han mostrado que a pesar del discurso que considera a animales no humanos como miembros de la familia, ellos siguen siendo vulnerables al abuso y la crueldad, debido a la falta de integración del sistema lega ${ }^{90}$. Incluso en textos modernos de Derecho de Familia es difícil encontrar mención a los animales no humanos con los que convivimos ${ }^{91}$. Ello contrasta con la pluralidad de estructuras familiares reconocidas actualmente por la sociedad ${ }^{92}$. Esto es particularmente notorio a nivel constitucional en Latinoamérica, en que la desvinculación de los conceptos de familia y matrimonio dan paso a un progresivo reconocimiento constitucional de la diversificación de la familia ${ }^{93}$. Así, se ha pasado de un modelo único de familia al reconocimiento de una pluralidad de modelos, todos ellos dignos de igual tutela ${ }^{94}$.

En definitiva, la paz se vuelve un aliado de la comunidad política al exigir que el Derecho regule de manera idónea el uso de la fuerza legítima contra todos sus miembros. Si los demás animales son los miembros más débiles de esta comunidad, el Derecho debe encontrar las formas de eliminar esa violencia estructural que ha sido creada por el Estado y los particulares. Qué mejor que sea el instrumento jurídico de más alta

\footnotetext{
${ }^{89}$ Op. cit. EISEN (2018) 909.

${ }^{90}$ LAMBACH FERREIRA DA COSTA, D. R., (in) efetividade da proteção dos animais de companhia: mais de uma forma de violência sob o mesmo teto, en Revista Latino-Americana de Direitos da Natureza e dos Animais 4/1 (2021), 135. https://periodicos.ucsal.br/index.php/rladna/article/view/877

${ }^{91}$ SUÁREZ, P., Animales, incapaces y familias multi-especies, en Revista Latinoamericana de Estudios Críticos Animales 2/4 (2017), 66. https://revistaleca.org/journal/index.php/RLECA/article/view/109/93

92 JARDIM GEISSLER, A. C., DISCONZI, N. \& SILVEIRA FLAIN, V., La mascota bajo la perspectiva de la familia multiespecie y su inserción en el ordenamiento jurídico brasileño, en Revista dA Derecho Animal (Forum of Animal Law Studies) 8/3 (2017), 3-4. https://revistes.uab.cat/da/article/view/v8-n3-disconzi-jardim-silveira/10

${ }^{93}$ ZÚÑIGA, Y. \& TURNER, S., Sistematización comparativa de la regulación de la familia en las constituciones latinoamericanas, en Revista de Derecho (Universidad Católica del Norte) 20/2 (2013), 298. https://revistaderecho.ucn.cl/index.php/revistaderecho/article/view/1955

${ }^{94}$ ESBORRAZ, D. F., El concepto constitucional de familia en América Latina. Tendencias y proyecciones, en Revista de Derecho Privado 29 (2015), 50. https://www.redalyc.org/pdf/4175/417543062002.pdf

52 Derecho Animal. Forum of Animal Law Studies, vol. 12/3
} 
jerarquía el que logre esa eliminación, incorporando en su texto protecciones y derechos para los animales no humanos, quienes forman parte de esta comunidad democrática, y también son destinatarios de las normas jurídicas que en ella se dictan.

\section{Conclusiones}

Aunque el Derecho y las constituciones son creaciones humanas, su aplicación y efectos alcanzan a millones de individuos que coexisten con nosotros en los territorios estatales: los demás animales. El antropocentrismo constitucional suele excluir por completo la protección y tutela intrínseca de todo lo no humano, pero gracias al denominado "giro político" del movimiento animalista, los límites de nuestra comunidad política entran hoy en tensión.

Desde un paradigma antropocéntrico, los conceptos de "habitantes" y "comunidad" sólo comprenden a seres humanos y sus intereses, aunque ni siquiera a todos cuando hablamos de "ciudadanía". Sin embargo, desde una comprensión profunda de nuestras relaciones con las demás formas de vida, es innegable que todos somos habitantes del planeta, y que en muchos casos formamos comunidad e incluso familia con ellos. Tal circunstancia es razón suficiente para que los textos constitucionales incorporen y protejan a los demás animales, considerando que por su carácter de seres sintientes, sus vidas también se ven afectadas por el poder político y estatal.

Una comprensión del Derecho, ya no como ley del más fuerte, sino como ley del más débil, permite aproximarnos a nuevos desafíos en materia de derechos fundamentales. Permite dar una respuesta racional ante los conflictos emergentes en los que están envueltos intereses de los demás animales. De ahí la importancia de desarrollar doctrina constitucional en materia de Derecho Animal, pero no desde cualquier enfoque, sino que, como hemos defendido hasta ahora, desde uno que supere el especismo.

La inclusión de los demás animales en la esfera constitucional va más allá de la lucha por el reconocimiento de sus derechos y constituye una invitación a comprender que la paz, como fin último del Derecho y en palabras de FERREYRA, "consiste en no dañar al otro, o en que nadie resulte dañado, o en que todos puedan tener la certeza de que no serán objeto de daño por parte del otro" 95 . Ello, indudablemente, debe alcanzar a los demás animales.

\section{Bibliografía}

- ALONSO, E., El artículo 13 del Tratado de Funcionamiento de la Unión Europea: Los animales como seres "sensibles [sentientes]" a la luz de la jurisprudencia del Tribunal de Justicia de la Unión Europea, en Animales y Derecho (Valencia 2015).

- ARANGO DURLING, V., Paz social y cultura de paz (Panamá 2007).

- BECERRA VALDIVIA, K., Competencias ciudadanas y animales no humanos: descentralizando el sujeto político, creando competencias ensambladas-ciudadanas, en Derecho Animal, tenencia responsable y otras propuestas interdisciplinarias (Santiago 2021).

- BENDOR, A. L., \& DANCING-ROSENBERG, H., Animals rights in the shadow of the constitution, en Animal Law 24/1 (2018). https://law.lclark.edu/live/files/32155-24-1-shadowpdf

- BLUE, G., \& ROCK, M., Animal publics: accounting for heterogeneity in political life, en Society \& Animals 22/5 (2014). https://doi.org/10.1163/15685306-12341350

- COULTER, K., Animals, work, and the promise of interspecies solidarity (New York 2016).

- DE LA TORRE TORRES, R. M., El bienestar animal como principio constitucional implícito y como límite proporcional y justificado a los derechos fundamentales en la Constitución mexicana, en dA. Derecho Animal (Forum of Animal Law Studies) 11/3 (2020). https://doi.org/10.5565/rev/da.506

- DECKHA, M., Constitutional protections for animals: A comparative animal-centred and postcolonial reading, en Colonialism and Animality (London 2020). https://doi.org/10.4324/9781003013891

- DE LA TORRE TORRES, R. M., Los fundamentos de los derechos de los animales (Ciudad de México 2021).

- DOMÉNECH PASCUAL, G., Colisiones entre bienestar animal y derechos fundamentales, en El derecho de los animales (Madrid 2015).

- DONALDSON, S. \& KYMLICKA, W., Zoopolis: A Political Theory of Animal Rights (New York 2011).

${ }^{95}$ Op. cit. FERREYRA (2018) 75. 
- DONALDSON, S., \& KYMLICKA, W., Rethinking Membership and Participation in an Inclusive Democracy: Cognitive Disability, Children, Animals, en Disability and Political Theory (Cambridge 2016). https://doi.org/10.1017/9781316694053.009

- DONALDSON, S. \& KYMLICKA W., Zoópolis, una revolución animalista (Madrid 2018).

- EISEN, J., Animals in the constitutional state, en International Journal of Constitutional Law 15/4 (2018). https://doi.org/10.1093/icon/mox088

- ESBORRAZ, D. F., El concepto constitucional de familia en América Latina. Tendencias y $\begin{array}{llllll}\text { proyecciones, en Revista de Derecho Privado } 29 & \text { (2015). }\end{array}$ https://www.redalyc.org/pdf/4175/417543062002.pdf

- FARACO, C., Interação humano-animal, en Ciência Veterinária nos Trópicos 11 (2008). https://www.bvs-vet.org.br/vetindex/periodicos/ciencia-veterinaria-nos-tropicos/11(2008)/interacao-humano-animal/

- FERRAJOLI, L., Razones jurídicas del pacifismo (Madrid 2004).

- FERRAJOLI, L., Principia iuris. Teoría del derecho y de la democracia: 1. Teoría del derecho (Madrid 2013a).

- FERRAJOLI, L., Principia iuris. Teoría del derecho y de la democracia: 2. Teoría de la democracia (Madrid 2013b).

- FERREYRA, R. G., Fundamentos constitucionales (Buenos Aires 2013a).

- FERREYRA, R. G., Sobre la constitución. Concepto, composición y mecanismos, en Revista de Derecho Político 86 (2013b). https://doi.org/10.5944/rdp.86.2013.12139

- FERREYRA, R. G., Sobre la coexistencia pacífica: propósito de un constitucionalismo ciudadano, en Academia, Revista sobre enseñanza del Derecho 16/31 (2018). https://dialnet.unirioja.es/servlet/articulo?codigo $=6867300$

- FOY VALENCIA, P., La constitución y el animal: aproximación a un estudio comparado, en Foro Jurídico 13 (2014). https://revistas.pucp.edu.pe/index.php/forojuridico/article/view/13784

- FRANCIONE, G., Animals, Property, and the Law (Philadelphia 1995).

- FRANCIONE, G., Animals as Persons: essays on the abolition of animal exploitation (New York 2008).

- GAETE ROJAS, S., Los Fines del Derecho, en Revista Chilena de Derecho 2 (1975). https://dialnet.unirioja.es/servlet/articulo?codigo $=2649248$

- GASSIOT, O., L'animal, nouvel objet du droit constitutionnel, en Revue française de droit constitutionnel 4/4 (2005). https://doi.org/10.3917/rfdc.064.0703

- GIMÉNEZ-CANDELA, T., Introducción, en Animales y Derecho (Valencia 2015).

- GIMÉNEZ-CANDELA, T., Transición animal en España (Valencia 2020).

- GONZÁLEZ MARINO, I., El fenómeno de las familias multiespecie y los desafíos que supone para el Derecho, en Personalidad jurídica de los animales no humanos y nuevas tendencias en Derecho animal (Santiago 2019).

- GONZÁLEZ MARINO, I., Hacia un principio de solidaridad ecológica e interespecies, en Revista Chilena de Derecho Animal 1 (2020). http://revistaderechoanimal.cl/wpcontent/uploads/2020/11/Israel-Gonzalez-Marino.pdf

- GUASTINI, R., Sobre el concepto de Constitución, en Cuestiones Constitucionales 1 (1999). http://dx.doi.org/10.22201/iij.24484881e.1999.1.5566

- HORTA, O., Un paso adelante en defensa de los animales (Madrid 2017).

- JARDIM GEISSLER, A. C., DISCONZI, N. \& SILVEIRA FLAIN, V., La mascota bajo la perspectiva de la familia multiespecie y su inserción en el ordenamiento jurídico brasileño, en Revista dA Derecho Animal (Forum of Animal Law Studies) 8/3 (2017), 3-4. https://revistes.uab.cat/da/article/view/v8-n3-disconzi-jardim-silveira/10

- KELSEN, H., Peace through Law (New Jersey 2000).

- LAMBACH FERREIRA DA COSTA, D. R., (in) efetividade da proteção dos animais de companhia: mais de uma forma de violência sob o mesmo teto, en Revista Latino-Americana de $\begin{array}{lllllll}\text { Direitos da Natureza } & \text { e } & \text { dos } & \text { Animais } & 4 / 1 & \text { (2021). }\end{array}$ https://periodicos.ucsal.br/index.php/rladna/article/view/877

- LE BOT, O., Les Grandes Évolutions du Régime Juridique de l'Animal en Europe: Constitutionnalisation et Déréification, en Revue québécoise de droit international, 24/1 (2011). https://doi.org/10.7202/1068304ar

- LE BOT, O., Is it useful to have an animal protection in the constitution?, en US-China Law Review 15/1 (2018). DOI:10.17265/1548-6605/2018.01.004 
- LEGGE, D. \& BROOMAN, S., Reflecting on 25 Years of Teaching Animal Law: Is it Time for an International Crime of Animal Ecocide?, en Liverpool Law Review 41 (2020). https://doi.org/10.1007/s10991-020-09253-0

- LOEWE HENNY, D.H., Integración de los animales no humanos en la comunidad política: zoopolis, en Revista Chilena de Derecho Animal 1 (2020). http://revistaderechoanimal.cl/wpcontent/uploads/2020/11/Daniel-Hans-Loewe-Henny.pdf

- MENÉNDEZ DE LLANO RODRÍGUEZ, N., La defensa de los animales desde el prisma constitucional, en Revista Chilena de Derecho Animal 1 (2020). http://revistaderechoanimal.cl/wpcontent/uploads/2020/11/Nuria-Menendez-del-Llano-Rodriguez.pdf

- MERCADO PÉREZ, D., La imposibilidad de definir el concepto de paz en el derecho, en Academia \& Derecho 15 (2018). https://doi.org/10.18041/2215-8944/academia.15.4334

- NAVA ESCUDERO, C., Los animales como sujetos de derecho, en dA. Derecho Animal (Forum of Animal Law Studies) 10/3 (2019). https://doi.org/10.5565/rev/da.444

- NUSSBAUM, M. C., Frontiers of Justice (Cambridge 2006).

- NUSSBAUM, M. C., Las fronteras de la justicia (Barcelona 2016).

- PAUCAR ESPINOZA, M., Protección animal: una reflexión constitucional, en Desde el Sur 5/1 (2012). https://biblat.unam.mx/hevila/DesdeelsurLima/2012-2013/vol5/no1/1.pdf

- PÉREZ LUÑO, A. E., Ciudadanía y definiciones, en Doxa: Cuadernos de Filosofía del Derecho 25 (2002). https://doi.org/10.14198/DOXA2002.25.05

- PEZZETTA, S., Derechos fundamentales para los demás animales. Especismo, igualdad y justicia $\begin{array}{llllll}\text { interespecies, en } & \text { Lecciones } & \text { y } & \text { Ensayos } & 100 & \text { (2018). }\end{array}$ http://www.derecho.uba.ar/publicaciones/lye/revistas/100/derechos-fundamentales-para-losdemas-animales.pdf

- PEZZETTA, S., Una teoría del derecho para los animales no humanos. Aportes para la perspectiva interna del Derecho, en Revista de Bioética y Derecho 44 (2018). https://doi.org/10.1344/rbd2018.0.20896

- PEZZETTA, S., El giro animal: impacto y desafíos para el derecho latinoamericano, en Revista Chilena de Derecho Animal 1 (2020). http://revistaderechoanimal.cl/wpcontent/uploads/2020/11/Silvina-Pezzetta-1.pdf

- POCAR, V., Los animales no humanos: por una sociología de los derechos (Buenos Aires 2013).

- PRIETO SANCHÍS, L., El constitucionalismo de los derechos: Ensayos de filosofía jurídica (Madrid 2013).

- RACHELS, J., The elements of moral philosophy (New York 2003).

- REGAN, T., The Case for Animal Rights (Berkeley 1983).

- REY PÉREZ, J. L., El enfoque político de los derechos de los animales desde la teoría de los derechos, en Revista Iberoamericana de Bioética 4 (2017). https://doi.org/10.14422/rib.i04.y2017.002

- REY PÉREZ, J. L., los derechos de los animales en serio (Madrid 2018).

- SINGER, P., Animal Liberation (New York 1975).

- SQUELla NARDUCCI, A., El Derecho y la fuerza, en Doxa 15/16 (1994). https://doi.org/10.14198/DOXA1994.15-16.40

- SQUELLA NARDUCCI, A., Introducción al Derecho (Santiago 2014).

- SUÁREZ, K. S., El Derecho a la paz y el derecho al servicio de la paz, en Revista Jurídica 32 (2018). https://www.revistajuridicaonline.com/wp-content/uploads/2021/05/32-7-EL-DERECHO-A-LAPAZ.pdf

- SUÁREZ, P., Animales, incapaces y familias multi-especies, en Revista Latinoamericana de $\begin{array}{lllll}\text { Estudios } & \text { Críticos } & \text { Animales } & 2 / 4 & \text { (2017), }\end{array}$ https://revistaleca.org/journal/index.php/RLECA/article/view/109/93

- VALENCIA RINCÓN, F., Derechos animales, solidaridad y derechos emergentes, en Icase. Revista de la Facultad de Derecho 109 (2020). http://dx.doi.org/10.14422/icade.i109.y2020.005

- VERNIERS, E., The impact of including animals in the constitution - Lessons learned from the German animal welfare state objective, en Global Journal of Animal Law 8 (2020). https://ojs.abo.fi/ojs/index.php/gjal/article/view/1691

- WISE, S., Sacudiendo la jaula: hacia los derechos de los animales (Valencia 2018).

- WOLF, U., Ética de la relación entre humanos y animales (Madrid 2014). 
- ZÚÑIGA, Y. \& TURNER, S., Sistematización comparativa de la regulación de la familia en las constituciones latinoamericanas, en Revista de Derecho (Universidad Católica del Norte) 20/2 (2013). https://revistaderecho.ucn.cl/index.php/revista-derecho/article/view/1955

\section{Jurisprudencia}

- SUPREMA CORTE DE JUSTICIA DE LA NACIÓN (SCJN), MÉXICO. 31 de octubre de 2019. Amparo en revisión 163/2018. Quejosos: Comisión mexicana de promoción gallística, asociación civil y Efraín Rábago Echegoyen.

https://bj.scjn.gob.mx/doc/sentencias_pub/dyVS3XgB_UqKst8os7a9/\%22Combatientes\%22\%20 